\title{
Transmyocardial Laser Revascularization. Early Clinical Experience
}

\author{
Sérgio Almeida de Oliveira, Luis Alberto Oliveira Dallan, Luiz Augusto F. Lisboa, \\ Maria Cristina Chavantes, Luis Antonio Machado Cesar, Miriam J. Pardi, Adib D. Jatene
}

São Paulo, SP - Brazil

\begin{abstract}
Objective - To analyze the initial clinical experience of transmyocardial laser revascularization (TMLR) in patients with severe diffuse coronary artery disease.
\end{abstract}

Methods - Between February, 1998 and February, 1999, 20 patients were submitted to TMLR at the Heart Institute (InCor), University of São Paulo Medical School, Brazil, isolated or in association with conventional coronary artery bypass graft (CABG). All patients had severe diffuse coronary artery disease, with angina functional class III/IV (Canadian Cardiovascular Society score) unresponsive to medical therapy. Fourteen patients were submitted to TMLR as the sole therapy, whereas 6 underwent concomitant $C A B G$. Fifty per cent of the patients had either been previously submitted to a $C A B G$ or to a percutaneous transluminal coronary angioplasty (PTCA). Mean age was 60 years, ranging from 45 to 74 years.

Results - All patients had three-vessel disease, with normal or mildly impaired left ventricular global function. Follow-up ranged from 1 to 13 months (mean 6.6 months), with no postoperative short or long term mortality. There was significant symptom improvement after the procedure, with $85 \%$ of the patients free of angina, and the remaining $15 \%$ of the patients showing improvement in functional class, as well as in exercise tolerance.

Conclusion - This novel technique can be considered a low risk alternative for a highly selected group of patients not suitable for conventional revascularization procedures.

Key words: myocardial revascularization, laser surgery, myocardial ischemia, surgery

Heart Institute - University of São Paulo Medical School, Brazil

Mailing adress: Sérgio Almeida de Oliveira - Incor - Av. Dr. Enéas C. Aguiar, 44 05403-000 - São Paulo, SP - Brazil
Until recently, a large number of patients with severely symptomatic diffuse coronary artery disease, and viable but ischemic myocardium, in whom conventional attempts to myocardial revascularization (either by angioplasty or coronary artery by passgraft (CABG)) had already been undertaken and failed, were left with no therapeutic alternatives.

Presently, since Wearn's et al ${ }^{1}$ description of myocardial sinusoids in human heart, many novel revascularization techniques to treat ischemia based on this particular coronary vascular architecture have been reported. In this sense, the direct implantation of the internal thoracic artery into the ischemic myocardium, as described by Vineberg ${ }^{2}$, in spite of being a success at the time, was soon abandoned, following the advent of direct revascularization with saphenous venous grafts ${ }^{3}$ and the internal thoracic artery anastomosis ${ }^{4}$.

Anatomic reports on compared anatomy showed that oxygenation and nutrition of the heart were accomplished mainly through communicating channels between the left ventricular cavity and sinusoid spaces, which are highly developed in some reptiles. In the human heart, the creation of channels communicating left ventricular cavity and sinusoids was first attempted by Sen et $\mathrm{al}^{5}$, using needles to perforate myocardium. Mirhoseini et $\mathrm{al}^{6}{ }^{6}$ were the first to test several different lasers to produce these channels, concluding that carbon dioxide laser caused less myocardial damage and permitted a longer duration of these channels. Based on that, they started an early experience with carbon dioxide laser associated with conventional $\mathrm{CABG}^{7}$.

In the beginning of this decade, a high-powered laser was developed (Heart laser, PCL Medical system Inc., Franklin, MA, USA), permitting its use in beating hearts, that is, without cardiopulmonary bypass. Results of a 15 patient pilot study with TMLR as an isolated procedure reported this technique to be safe and effective to improve angina symptoms. A large non-randomized trial in eight centers soon followed, reporting the results of TMLR on 201 patients with angina functional class III/IV unsuitable 
for conventional surgery or PTCA. Results were highly encouraging, with a short-term mortality of $9 \%$, a long-term (one year) survival of $83 \%$, and significant symptom improvement in $75 \%$ of the patients ${ }^{8}$. Due to these favorable results, a prospective, randomized, multicenter trial was subsequently performed in 1995, to compare TMLR with medical therapy ${ }^{9}$. In this trial, all patients had angina functional class III/IV and diffuse coronary artery disease unsuitable to conventional surgery or PTCA. Cross over from medical treatment to surgical treatment was permitted in case of worsening of symptoms requiring admission to a Coronary Care Unit for over 48 hours. After a 12 month follow-up, results disclosed a better outcome for TMLR when compared to medical treatment, with improvement in angina symptoms, quality of life and myocardial perfusion ${ }^{9}$. In August 1998, the FDA finally approved TMLR as an alternative procedure to treat patients unsuitable for conventional surgery or PTCA. In Brazil, TMLR was first attempted by Galantier et al, in April, 1995, and results presented at the $23^{\text {rd }}$ Brazilian Congress of Cardiovascular Surgery.

\section{Methods}

In the present study, we will report the initial experience of a series of 20 patients submitted to TMLR as a sole procedure or associated to CABG at the Heart Institute, University of São Paulo, Brazil.

Between February, 1998 and February, 1999, 20 patients, 16 male, mean age of 60 years (ranging from 45 to74 years) were submitted to TMLR. All of them had multivessel disease, and left ventricular ejection fraction by echocardiogram $\geq 0.45$. They all had severely compromised coronary arteries, with diffuse disease unsuitable for coronary surgery or PTCA. Twelve patients had stable angina, while 8 had unstable angina (fig. 1). TMLR was the sole procedure in 14 patients, whereas 6 patients were also submitted to CABG, since some coronary arteries, although critically diseased, could still be directly revascularized. Ten patients had previously undergone CABG (table I).

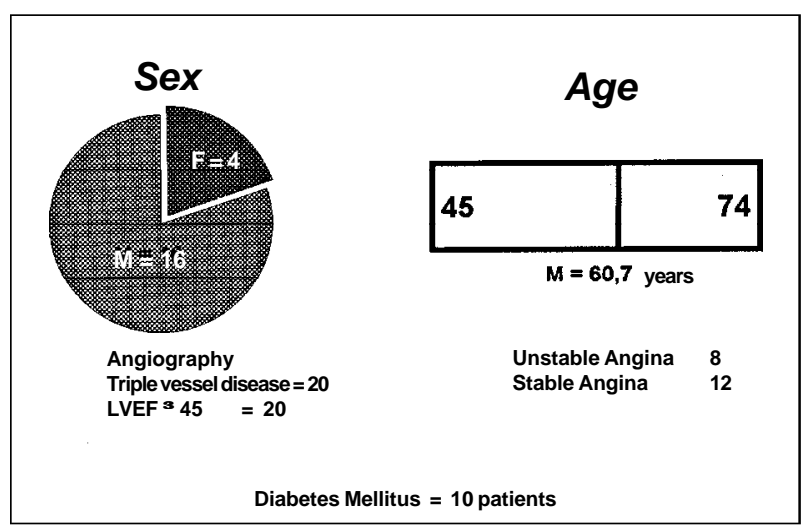

Fig. 1 - Demographic distribution and pre-operative characteristics of 20 patients who underwent transmyocardial revascularization
All these patients had angina functional class III/IV, refractory to medical therapy. They all had documented ischemia by Thallium scintilography or dobutamine stress echocardiography.

Patients were excluded from the study if they had a recent myocardial infarction, chronic obstructive pulmonary disease or significant ventricular arrhythmias refractory to drug therapy. Patients with severe congestive heart failure and left ventricular ejection fraction $<0.45 \%$ were also excluded from the study.

Surgery was undertaken under general anesthesia after orotracheal intubation. After anesthesia all patients were continuously monitored with a pulmonary artery catheter and a transesophageal echocardiography (TEE) probe to assess left ventricular function. In addition, TEE was used to assure that laser had indeed penetrated into the left ventricular cavity. In those patients in whom only TMLR was performed, access to the heart was accomplished using a left anterolateral thoracothomy, through the $4^{\text {th }}$ or $5^{\text {th }}$ intercostal space. A pericardial incision was carried out anterior to the phrenic nerve, with ample exposition of the left ventricular anterior, lateral and inferior walls. A classical approach to the heart was performed in those patients who were submitted to conventional $\mathrm{CABG}$ as well as the TMLR, followed by implantation of arterial and venous grafts. Laser application was delivered after interruption of cardio-pulmonary bypass and reversion of anticoagulation with protamine sulfate.

The laser utilized was a 800-W carbon dioxide laser device (PCL medical systems, Milford, Ma. USA). Laser pulses were synchronized to the electrocardiogram at the peak of the $\mathrm{R}$ wave, in order to reach the heart during its refractory period thus avoiding arrhythmias and permitting its penetration into the left ventricular cavity during diastole. Considering that laser has a low liquid penetration, as soon as it reached blood into the left ventricle, there would be energy dissipation and gas production, observed by TEE as bubbles, thus confirming laser penetration into the left ventricular cavity. Pulse energy used ranged from 20 to 30 joules, and the number of channels or effective perforations ranged from 15 to 51 , with an average of 31 perforations per patient (fig. 2). At the site of perforation there a slight self-limited bleeding, which ceased completely after a mild external compression. A hemostatic suture was seldom necessary. Laser application was restricted to the ischemic areas, to avoid damage to larger epicardial arteries as well as veins.

\begin{tabular}{|lccc|}
\hline \multicolumn{4}{|c|}{$\begin{array}{c}\text { Table I - Type of surgery in patients who underwent } \\
\text { transmyocardial revascularization (20 patients) }\end{array}$} \\
\hline & Laser & Combined & Total \\
\hline & 6 & 4 & 10 \\
$1^{\text {st } \text { Operation }}$ & 8 & 2 & 10 \\
Reoperation & 14 & 6 & 20 \\
Total & & 6 & \\
\hline
\end{tabular}


Throughout the whole procedure and in the first 24 post-operative hours, the patient received intravenous nitroglycerin. Average length of stay at the Intensive Care Unit depended on the surgical procedure undertaken, being 24 hours for isolated TMLR, and two days for combined procedures (TMLR and CABG).

\section{Results}

Initial results of this series of patients were extremely satisfactory, with no early postoperative or long-term mortality (follow-up ranged from 1 to 13 months, mean of 6.6 months). No major complications such as myocardial infarction were observed in these patients; additionally, no patient required to be reoperated upon due to bleeding. One patient with a previous $C A B G$ had a prolonged episode of chest pain in the second postoperative day but no creatine kinase-MB fraction elevation or perioperative $\mathrm{Q}$ wave infarction on the ECG; his preoperative coronary angiography revealed a pervious but severely diseased saphenous venous graft to the first diagonal branch and this episode was thus interpreted as caused by a probable occlusion of this graft. All patients were submitted to Thallium scintigraphy during the immediate postoperative phase, with five patients also submitted to dobutamine stress echocardiography, however, these examinations did not show any improvement in myocardial perfusion, when

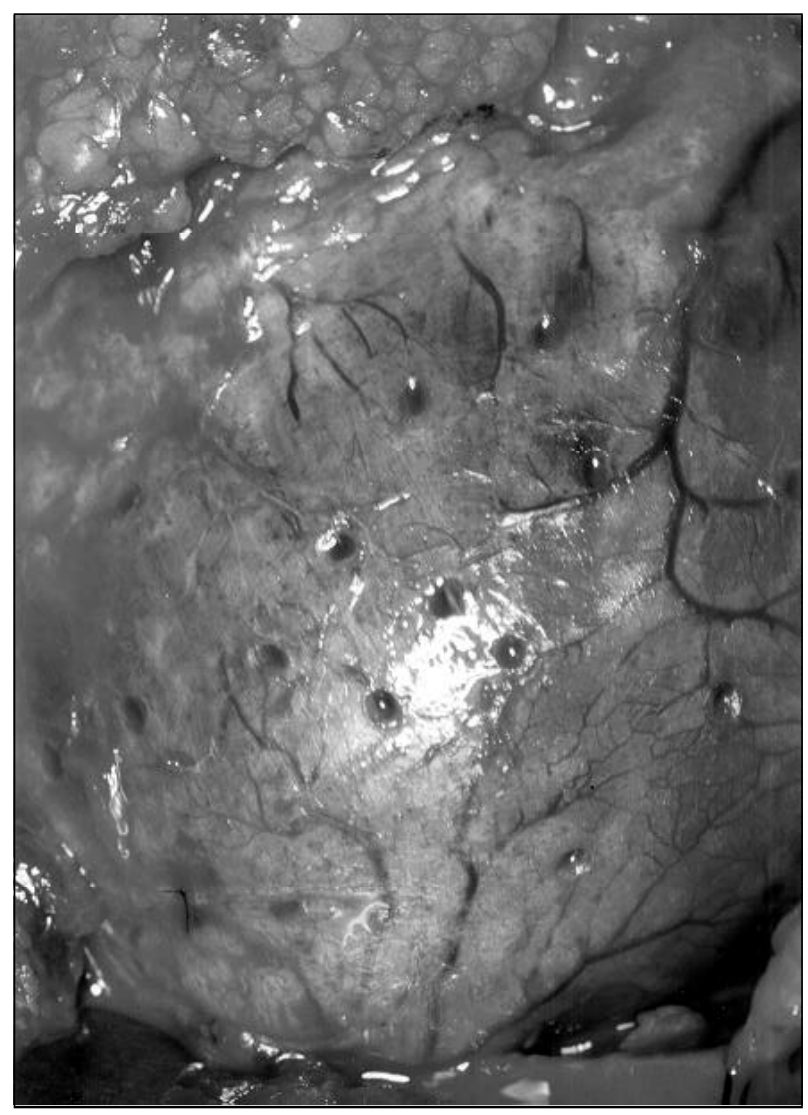

Fig. 2 - Picture of the operative field showing the channels created in the left ventricular wall by the carbon dioxide laser. compared to preoperative perfusion studies. Another patient, who still presented mild angina symptoms postoperatively, was submitted to a new coronary angiography three months after the TMLR. He had previously undergone both CABG and PTCA and was eventually submitted to TMLR as the sole therapy. The subsequent coronary angiography disclosed similar findings to the preoperative examination. A diabetic and obese patient with preoperative refractory angina, as well as congestive heart failure medically controlled, had to be readmitted to hospital two months after the procedure to treat heart failure symptoms. This patient was free of angina at that time.

In relation to angina symptoms, there was an extremely favorable evolution, since all patients improved functional class. As shown on Figure 3, all patients presented with angina functional class III/IV preoperatively. After surgery, 17 patients were angina free and only three had angina during moderate to strong exertion. All of them reported improvement in physical activity. Two of these three still symptomatic patients had been submitted to TMLR as a sole procedure and one had undergone a previous CABG. It is important to note that although mean follow-up time is still short, angina relief has been progressive, that is, symptoms have improved with time.

\section{Discussion}

TMLR, recently utilized as an alternative myocardial revascularization strategy, has developed very fast, even before scientific uncertainties regarding the mechanism of its effectiveness have been completely elucidated. The most likely reason for that are the favorable results reported by several trials, mainly due to the substantial group of patients with severe coronary artery disease previously submitted to revascularization procedures. Patients with viable but ischemic myocardium and refractory angina are a great challenge to physicians, who need to find means to improve their clinical status, since they are unsuitable for further conventional revascularization procedures. In our series of twenty patients, there were no deaths, which is in agreement with literature reports. Mortality is mainly related

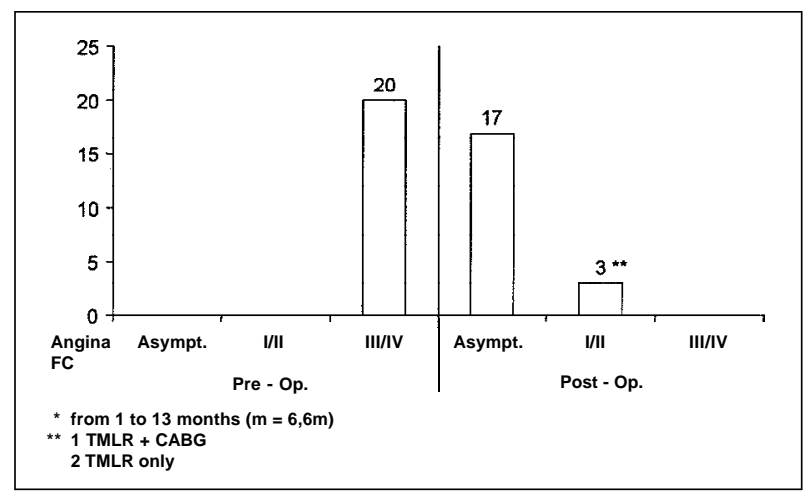

Fig. 3 - Angina functional class before and after transmyocardial revascularization in 20 patients (mean follow-up of 6.6 months) 
to unstable clinical symptoms, with mortality risk higher when the procedure is performed during an acute episode of unstable angina. March ${ }^{9}$ has reported an immediate mortality rate of $27 \%$ if patients were operated on during 1 to 7 days of an episode of unstable angina. Mortality rate was reduced to $16 \%$ when this interval was 8 to 14 days and to $1 \%$ if the surgery was performed 15 days after the event. In our series, although eight patients had a clinical diagnosis of unstable angina, none was confined to a Coronary Care Unit or was receiving intravenous heparin or nitroglycerin. In this multicenter trial, which compared TMLR to medical treatment, $60 \%$ of the patients who were initially candidates for medical treatment had to cross over to TMLR, due to worsening of symptoms. These patients were probably responsible for the highest mortality rates in patients operated on early after an unstable angina event.

The most surprising outcome in our study was the remarkable angina relief reported. Before the operation patients had rest or minimal exertion angina, which disappeared in $85 \%$ of the patients or improved in functional class in the others, during a follow-up of 1 to 13 months. Along with the improvement in angina symptoms, there was also a significant improvement in exercise tolerance after the procedure. Larger studies have also shown that this improvement is progressive during the first year and persists during a three year follow-up ${ }^{11}$.

Several reports have also demonstrated an improvement in myocardial perfusion. Cooley et al ${ }^{12}$ have shown a significant improvement in myocardial perfusion by positron emission tomography scan. This prospective, randomized study, which compared TMLR with medical management has yielded very interesting results concerning myocardial perfusion studies. Results show that after a 12 month follow-up, $20 \%$ of the patients submitted to TMLR had an improvement in myocardial perfusion, as shown by Thallium perfusion studies, compared to a $27 \%$ worsening in those patients who were medically managed.

Controversies still remain concerning the patency of the channels which communicate sinusoids to the left ventricular cavity, and if these channels could contribute to the transportation of blood to ischemic areas in order to improve myocardial perfusion. While long-term patency of lasercreated channels has been confirmed by some authors ${ }^{13}$, others have shown lack of perfusion through these channels ${ }^{14,15}$. A very important finding shown in a number of autopsies and experimental reports in laboratory animals has been the description of angiogenesis, possibly stimulated by laser application to the left ventricular myocardium. Evidence of laser-induced angiogenesis has been established by several studies ${ }^{16-19}$. In addition, it has been hypothesized the laser lesion might produce an inflammatory response in the myocardium, with citokines and growth factors release along with receptors stimulation ${ }^{16}$. Conversely, it remains to be elucidated whether this inflammatory response inducing angiogenesis is in effect a non-specific response to repetitive myocardial trauma produced by laser. Chu and $\mathrm{al}^{20}$ decided to test in pig hearts if mechanical transmyocardial revascularization created with needles could induce a response similar to that created by the laser application. They observed, however, that although the metabolic response was similar, three times more perforations were necessary to obtain the same capillary density as laser-induced angiogenesis.

Another possible explanation for clinical improvement after TMLR is the cardiomyocite denervation. An experimental study by Sundt and Kwong ${ }^{21}$ shows that TMLR with Holmium: YAG laser in dogs can destroy the cardiac nervous network and that might contribute to the improvement in angina frequently observed in patients submitted to this procedure. Although it is not possible to rule out this hypothesis altogether, it is difficult to believe that denervation should play an important role. Cardiac nerve fibers destruction might in fact cause a greater damage, since with the lack of angina, the patient would be more exposed to ischemic injury, increasing the risk of myocardial infarction or sudden death, a fact that has not been observed in patients submitted to TMLR.

Another possibility, a placebo effect, is also unlikely since the benefits would not be sustained for a year or more, and no progressive improvement would be observed.

Finally, it is possible that the beneficial effects of TMLR are due to multiple mechanisms, such as the perfusion through laser careated channels, angiogenesis, cardiac denervation or the placebo effect. In this sense, experimental research on genetic therapy with myocardial injections of angiogenic growth factors has recently been initiated ${ }^{22}$. To further clarify these mechanisms, research on laser therapeutics and angiogenesis is underway. Meanwhile, these two strategies can be combined for greater efficiency ${ }^{23}$.

A prospective, randomized, multicenter trial comparing direct coronary revascularization as an isolated therapy with surgery associated with TMLR (Holmium: YAG laser) has been reported with very interesting results. Two hundred and twenty one potential candidates for conventional revascularization could be enrolled in this trial. These patients also had additional ischemic myocardial territories unsuitable for coronary bypass, and they were thus randomized into two distinct groups: one group had coronary bypass grafts performed to amenable arteries with concomitant TMLR employed in the areas that could not be revascularized, whereas the other group only had coronary artery bypass grafts, leaving the remaining ischemic areas unprotected. Predicted in-hospital and 30 days mortality rate, as determined by Parsonnet test, were 8.8 and $8.4 \%$, for each group respectively. However, postoperative mortality was significantly lower for the group with combined procedures $(0.9 \%)$ than for the group submitted to CABG alone (7\%). In summary, TMLR as a complement to conventional $\mathrm{CABG}$ has been established as a safe alternative to reduce mortality risk in those patients who are unsuitable for coronary revascularization ${ }^{24}$.

Considerable expectations have been created by these novel therapeutic strategies, mainly for those patients with 
end-stage obstructive coronary disease, for whom new hopes are now emerging.

In conclusion, TMLR as an isolated procedure or combined with conventional surgery can offer satisfactory results for a selected subgroup of patients. An improvement in angina symptoms and exercise tolerance can be observed in all patients, making TMLR a potential alternative for highly symptomatic patients with coronary artery disease not amenable to revascularization by conventional procedures.

\section{References}

1. Wearn JT, Mettler SR, Klumpp TG, Zschieche LJ. The nature of the vascular communications between the coronary arteries and the chambers of the heart. Am Heart J 1933; 9: 143-64.

2. Vineberg A. A clinical and experimaental study in the treatment of coronary artery insufficiency by internal mammary artery implant J Intern Coll Surg 1954; 22: 503-18.

3. Favaloro RG. Saphenous vein autograft replacement of severe segmental coronary artery occlusion. Operative technique. Ann Thorac Surg 1968; 5: 33

4. Green GE, Stetzer SH, Reppert EH. Coronary arterial bypass grafs. Ann Thoarc Surg 1998; 5: 443-50.

5. Sen PK, Udwadia TE, Kinare SG, Parulkar GB. Transmyocardial acunpuncture, a new approach to myocardial revascularization J Thorac Cardiovasc Surg 1965; 50: 181-9.

6. Mirhoseini M, Fisher JC, Cayton MM. Myocardial revascularization by laser. A clinical report. Lasers Surg Med 1983; 3: 241-5.

7. Mirhoseini M, Schelgikar S, Cayton MM. New conceptsin revascularizationof the myocardium. Ann Thorac Surg 1988; 45: 415-20.

8. Horvath KA, Cohn LH, Cooley DA, et al. Transmyocardial laser revascularization: Results of a multicenter trial with transmyocardial laser revascularization used as a sole therapy for end-stage coronary artery disease. J Thorac Cardiovasc Surg 1997; 113: 645-54.

9. March RJ. Transmyocardial laser revascularization with the $\mathrm{CO} 2$ laser: One year results of a randomized, controlled trial. Seminars Thorac Cardiovasc Surg 1999; 11: $12-18$.

10. Galantier M, Moreira GB, Bub RF, et al. Revascularização transmiocárdica a laser. Rev Bras Cir Cardiovasc 1996; 11: 67-74.

11. Horvath KA, Cohn LH, Cooley DA, et al. Functional improvement, long term survival and angina relief after transmyocardial revascularization with a $\mathrm{CO} 2$ laser. Circulation 1998; 89(suppl I): I-217.

12. Cooley DA, Frazier OH, Kadiipasaoglu KA, et al. Transmyocardial lase revascularization: Clinical experience with 12-mounth follow-up. J Thorac Cardiovasc Surg 1996; 111: 791-9.

13. Cooley DA, Frazier OH, Kadipasoglu KA, Pehlivanoglu S, Shannon RL,
Angellini P. Transmyocardial laser revascularization: Anatomic evidence of long-term channnel patency. Tex Heart Inst J 1994; 21: 220-4.

14. Sigel JE, Abramovich MD, Lytle BW, Ratiliff NB. Transmyocardial laser revascularization: Three sequential autopsy cases. J Thorac Cardiovasc Surg 1998; 115: 1381-5.

15. Burkhoff D, Fisher PE, Apfelbaum M, et al. Histologic appearance of transmyocardial laser channels after 4 1/2 weeks. Ann Thorac Surg 1996; 61:1532-5.

16. Roethy W, Yamamoto N, Burkhoff D. An examination of potential mechanisms underlying transmyocardial laser revascularization induced increases in myocardial blood flow. Seminars Thorac Cardiovasc Surg 1999; 11: 24-8.

17. Spanier T, Smith CR, Burkhoff D. Angiogenesis: A possible mechanism underlying the clinical benefits of transmyocardial laser revascularization. J Clin Laser Med Surg 1997; 15: 269-73.

18. Mack CA, Patel SR, Rosengarten TK. Myocardial angiogenesis as a possible mechanism for TMLR efficacy. J Clin Med Surg 1997; 15: 275-9.

19. Pelletier MP, Giaid A, Sivaraman S, et al. Angiogenesis and growth factor expression in a model of transmyocardial revascularization. Ann Thorac Surg 1998; 66: 12-18.

20. Chu V, Giaid A, Kuang J, et al. Angiogenic response to transmyocardial revascularization (TMR): Laser versus mechanical punctures. Presenter at the Annual Meeting of the Society of Thoracic Surgeons, January 1999.

21. Sundt TM, Kwong KF. Clinical experience with the holmuium:YAG laser for transmyocardial laser revascularization and myocardial denervation as a mechanism. Seminars Thorac Cardiovasc Surg 1999; 1: 19-23.

22. Sayeed-Shah U, Reul RM, Byrne JG, Aranki SF, Cohn LH. Combination TMR and gene therapy. Seminars Thorac Cardiovasc Surg 1999; 11: 36-9.

23. Lee LY, Rosengarten TK. Transmyocardial laser revascularization and angiogenesis: The potential for therapeutic benefit. Seminars Thorac Cardiovasc Surg 1999; 11: 29-35.

24. Allen KB, Delrossi AJ, Realyvasquez F, Lefrak EA, Shaar CJ, Dowling RD. Transmyocardial revascularization combined with coronarary artery bypass grafting versus coronarary artery bypass grafting alone. Results of a Prosperctive Randomized, Multi-Center Trial. Circulation 1998; 98(suppl I) I-217. 